\begin{tabular}{|c|c|c|}
\hline & $\begin{array}{c}\text { European Association for the } \\
\text { Development of Renewable Energies, Environment } \\
\text { and Power Quality (EA4EPQ) }\end{array}$ & $\begin{array}{l}\text { International Conference on Renewable Energies and Power Quality } \\
\text { (ICREPQ'12) } \\
\text { Santiago de Compostela (Spain), 28th to 30th March, } 2012\end{array}$ \\
\hline
\end{tabular}

\title{
Voltage Dip Immunity of Equipment and Installations Messages to stakeholders
}

\author{
M. Bollen ${ }^{1}$, S. Cundeva ${ }^{2}$, R. Neumann ${ }^{3}$ J. Gordon $^{4}$, S. Djokic ${ }^{5}$, K. Stockman ${ }^{6}$, G. Ethier ${ }^{7}$, and K. van Reussel ${ }^{8}$ \\ ${ }^{1}$ Luleå University of Technology, Skellefteå, Sweden \\ e-mail: math.bollen@stri.se \\ ${ }^{2}$ Sts Cyril and Methodius University, Faculty of Electrical Engineering and IT, Skopje, Macedonia \\ e-mail: scundeva@feit.ukim.edu.mk \\ ${ }^{3}$ Qualitrol, Belfast, UK \\ e-mail: rneumann@qualitrolcorp.com \\ ${ }^{4}$ Endesa, Sevilla, Spain \\ e-mail: josemaria.romero@endesa.es \\ ${ }^{5}$ Univ. of Edinburgh, Edinburgh, UK \\ e-mail: sasa.djokic@ed.ac.uk \\ ${ }^{6}$ Hogeschool West Vlaanderen, Kortrijk, Belgium \\ e-mail: Kurt.Stockman@howest.be \\ ${ }^{7}$ Hydro Quebec, Montreal, Canada \\ e-mail: Ethier.Gaetan@hydro.qc.ca \\ ${ }^{8}$ KU Leuven, Leuven, Belgium \\ e-mail: Koen.VanReusel@esat.kuleuven.be
}

\begin{abstract}
This paper presents the messages to the stakeholders on voltage-dip immunity as extracted by UIE WG2 from CIGRE TB412 [1]. The paper summarizes the main recommendations from this technical brochure in the form of messages towards regulators, standard-setting-organizations, network operators, industrial customers, equipment manufacturers, and power quality monitor manufacturers, researchers.
\end{abstract}

\section{Key words}

Power quality, electromagnetic compatibility, voltage dips, equipment immunity.

\section{Introduction}

Voltage dips (also known as "voltage sags”) are shortduration reductions in voltage magnitude. Their duration is typically between a few cycles of the power-system frequency and a few seconds. The interest in voltage dips is mainly due to their impact on end-user equipment.
Industrial processes may malfunction or shut down due to a voltage dip resulting in significant financial losses.

Voltage dips are due to short-duration increases in current magnitude, whereas voltage dips due to short circuits and earth faults are of most concern for customers.

International Joint Working Group (JWG) C4.1110 sponsored by CIGRE, CIRED and UIE has addressed a number of aspects of the immunity of equipment and installations against voltage dips and also identified areas were additional work is required. The work took place between 2006 and 2009 and resulted in a technical brochure distributed via CIGRE and UIE [2].

This paper summarizes the main conclusions from the technical brochure resulting in recommendations towards the main stakeholders involved in voltage dip immunity. Each of the following sections represents one of the nine identified stakeholders. The individual messages can be 
obtained from the website of the Union of Electricity Applications (UIE) [2].

\section{Message to regulators}

\section{A. The occurrence of voltage dips is part of the normal operation of any power system}

Voltage dips occur at almost all locations in the power system and avoiding them is only practically possible up to a certain extent. Avoiding dips altogether is not possible. Reducing the number and severity of voltage dips experienced by a customer, beyond what is normally considered as good engineering practice, can be very expensive. The global voltage-dip database built by the working group has shown among others that there is a large variation among individual sites in number of voltage dips per year. This is due to differences in network topology but also for example due to differences in weather conditions.

\section{B. Monitoring and recording of voltage dips is needed}

Voltage dips exceeding a certain severity will result in large economic losses for industrial customers. Different mitigation methods are available to limit the costs due to process interruptions. The economic optimum is not the same for different customers, among others depending on the number of voltage dips. This is one of the reasons why data on number and severity of voltage dips is needed. Such data will also allow network operators to make the right investments to limit number and severity of dips, where practically possible. The data needed can be obtained by using voltage-dip monitoring at different locations in the network. The recording of voltage dips, using automatic monitoring equipment, is the only widelyaccepted method for obtaining this data. Measurement at each connection point is typically not practical, but multiple measurement locations within the area of one network operator are in most cases needed. The number of measurement locations needed depends strongly on the local properties.

\section{Regulators should provide the incentives to facilitate voltage-dip monitoring by network operators}

Next to price of electricity and continuity of supply, voltage dips are the issue that most affects customers. Although the number of customers severely affected by voltage dips is limited, the economic impacts make the voltage-dip performance of the network an important property that should be monitored. The costs of monitoring include: the costs of the monitoring equipment; the costs the processing of the data so that it can be used by the customers; and the costs of interacting with the customer. The network operator should be able to recover these costs.

The network operator should provide the data in a suitable format to its customers, when requested by the customer. A possible format is proposed in the working-group report. This data will allow the customer to make investment decisions based on facts. The regulator should facilitate the availability of this data for the customer.

\section{Message to standard-setting- organizations}

\section{A. Characteristics of voltage dips}

The main items that describe voltage dips have been listed in the report. Apart from minimum voltage and duration, which are already defined in several standards, some other variables and concepts should be defined in future standards, such as transition and event segments, phase-angle jump, three-phase unbalance, waveform distortion, point-on-wave, rate-of-change of voltage, etc. These added characteristics will make voltage dip analysis more systematic. The most important characteristic still undefined is the unbalance of the dip.

The classification proposed by the working group distinguishes between three types of dips, where Type I and Type II are unbalanced and Type III is balanced:

- Type I is a drop in voltage that takes place mainly in one of the phase-to-ground voltages.

- Type II is a drop in voltage magnitude that takes place mainly in two phase-to-ground voltages.

- Type III is a drop in voltage magnitude that is equal for the three phase-to-ground voltages.

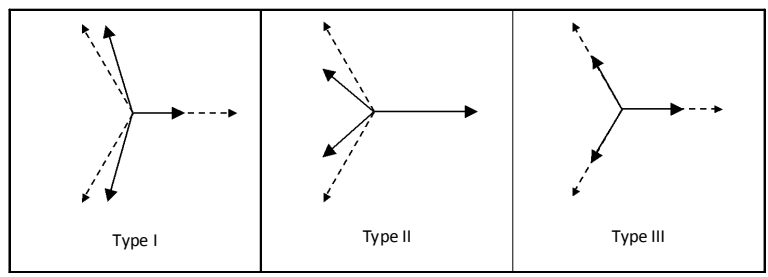

Fig. 1. Phasor diagrams for the proposed dip types.

Detailed algorithms for making such distinction have been proposed and will be forwarded to the relevant standard-setting groups. Measurement standards are needed to include the three channels in the measurement and to record more than just one residual voltage and one duration.

\section{B. Global statistics show a non-negligible number of Type III dips}

A global database of voltage-dip statistics has been created. This database includes statistics from several countries on several continents, counting 1175 sites. The results of the database analysis are presented as a set of contour charts for Type I, Type II and Type III dips. The number of voltage dips varies significantly for different sites, so a percentile method is used to describe worstcase sites (95-percentile), median sites (50-percentile), and so on.

Based on the results of that database it was concluded that Type III dips are not negligible: they make up 20\% of the dips at MV and HV sites in the database. This type of dips is not covered by existing standards, even though 
its effect on end-user's equipment is typically more severe. Therefore a recommendation is raised for studying and including Type III dips in the standards.

\section{Dip Immunity Labels}

The global voltage dip database shows a large variation in number of dips between locations. The economic losses due to a process interruption vary a lot between different processes. The economically-optimal equipment immunity is different at different locations, whereas the market at the moment does not offer a choice in voltage-dip immunity of equipment. Five different immunity classes are proposed by the working group to offer this choice.

The Working Group further introduced a useful new concept, "process-immunity time", making a distinction between equipment failure and process failure. This distinction allows better economic assessment of the impact of dips on industrial installations. This led to the need for an equipment performance criterion together with the immunity class.

Combining the immunity class and the performance criterion, results in the proposed "voltage-dip immunity label”, as shown in the table in Figure 2 below.

\begin{tabular}{|c|c|c|c|c|}
\hline \multirow{2}{*}{\multicolumn{2}{|c|}{$\begin{array}{c}\text { Voltage dip } \\
\text { immunity label }\end{array}$}} & \multicolumn{3}{|c|}{ Equipment performance criteria } \\
\hline & & Full operation & Self-recovery & Assisted-recovery \\
\hline \multirow{5}{*}{ 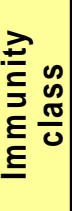 } & A & & & \\
\hline & B & & & \\
\hline & C1 & & & \\
\hline & C2 & & & \\
\hline & D & & & \\
\hline
\end{tabular}

Fig. 2. Proposed voltage dip immunity label.

These labels will simplify communication between equipment manufacturers and equipment end-users about dip immunity, while at the same time allowing equipment end-users a sufficient level of choice in selecting equipment. Test levels (combinations of duration and voltage magnitude; for each of the three types of dips) for five different immunity classes are proposed. As an example Class B is shown in Figure 3 below.
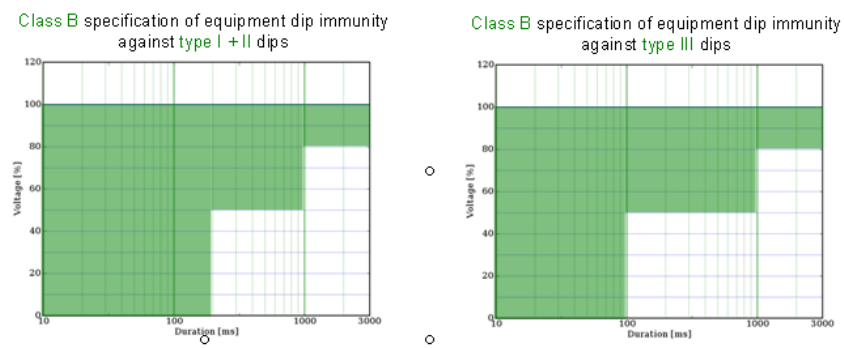

Fig. 3. Proposed immunity against voltage dips of Type I+II and Type III respectively (example for Class B).

\section{Message to network operators}

\section{A. Voltage dips are a main concern for industrial customers after reliability}

Knowing that network operators can not avoid all faults on the grid and that voltage depth and duration are set by the network itself, the number of fault on their network part is the only one factor that network operators can handle at a certain amount. There is no normal numbers of voltage dips in a grid, thus network operators are ask to keep them as low as possible. To limit the number of fault, network operators can deploy good engineering practices from standards of their industry at economical cost to save losses to all end-users connected to their grid.

\section{B. Voltage dips may result in serious economic loss for many industrial customers}

A large fraction of the voltage dips that result in process interruptions are due to faults in the grid. This includes the grid on the customer premises, the distribution grid and the transmission grid. Since these faults are not directly on the line of the affected customers it results in a voltage dips instead of an interruption, but their impact on processes still cause economical damages. Processes are not limited to industrial processes but to everything that could lead to economical losses for industrial, commercial, services and building management.

\section{Mutual understanding}

Mutual understanding of origin and consequences of voltage dips is an essential basis for jointly addressing the compatibility between the network and the industrial installation. Since voltage dips are largely dependent of many factors (voltage level, weather, overhead lines, network configuration, etc), recording should take place in different part of the network and as close as possible of the customers. Even if network operator can not avoid all faults in the grid, the recording of voltage dips is essential for mutual understanding.

\section{Customers need data}

Customers need data on number and severity of voltage dips to improve immunity. From a customer point of view, voltage dips happen more often then interruptions and consequences on their processes are immunity dependent. To solve voltage dips customer complaints, cooperation between the stakeholders is essential. Customers need that network operators provide records of voltage dips. Characterisation of voltage dips is the first step to improve the immunity of any process. The report of the working group has shown the needs for two kind of data presentation, one to address the customer complaints and where the data is plot in a scattered graph and a second need for global grid survey where contour chart and percentile are more useful. 


\section{Message to industrial customers}

A. The occurrence of voltage dips is part of the normal operation of a power system

Voltage dips are the result of large currents in the grid due to faults, lightning or starting of large motors. The duration and depth of the dip experienced by an industrial customer depends on the network topology, the distance to the fault location and the settings of the fault clearing devices in the grid. As a result, voltage dips cannot be eliminated from the normal operation of the grid. However, as the number of dips can vary strongly between locations this information can impact the choice of the location for new installations. In most cases, network operators can provide indicative data on the number of voltage dips and their severity to be expected.

\section{B. Improving the immunity of installations against voltage dips should be based on economic considerations}

Every industrial installation is exposed to voltage dips. A voltage dip may or may not result in a process interruption, depending on the type and design of the installation. Whether a process interruption can be tolerated or not, highly depends on its economic impact: loss of revenue, additional working hours, lost material; damage to the installation; etc. The costs of any mitigating measure have to be balanced against the economic impact of the dips.

It should be emphasized that not always the required investments are high. For example, supplying low power control devices by means of an UPS can drastically improve dip immunity at fairly reasonable costs and result in substantial financial savings.

\section{Dips should be considered during the design of an installation}

Considering the impact of voltage dips during the design stage of a new process is recommended. The working group document proposes a methodology to set up the required analysis to improve process behaviour. The methodology also holds to analyse and immunize existing processes.

Each piece of equipment in the installation is linked to the process parameter it is governing. For each equipment and related process parameter, the Process Immunity Time is determined as the time before the process parameter goes out of specifications. The shorter the Process Immunity Time the more critical the equipment is. By setting up this analysis, the amount of equipment to be improved can be limited to the strict minimum. This methodology results in a list of specifications for electrical equipment. This can next be communicated to the equipment manufacturer. The Process Immunity Time methodology is described in detail in the above-mentioned final report.
D. Cooperation between process and electrical engineers is essential to solve voltage-dip problems

The concept of Process Immunity Time to detect the most critical equipment within a process is based on the knowledge of process parameter behaviour as well as on knowledge of the electrical installation. Setting up this analysis requires cooperation between electrical engineers, process engineers, and instrumentation engineers to obtain reliable information. This cooperation also results in a better mutual understanding among the different engineering disciplines within a company, allowing further process improvements.

\section{Message to equipment manufacturers}

\section{A. Development of new equipment}

Manufacturers should consider voltage-dip immunity of their equipment at an early stage in the process of development of new equipment. Voltage dips are complex disturbances that should be characterized not only by magnitude and duration. To assist the manufacturer in assessing the potential impact of voltage dips on their equipment behaviour, a check-list of voltage-dip characteristics is provided in the abovementioned final report.

\section{B. Knowledge the immunity of equipment against voltage dips}

Customers need to know the immunity of equipment against voltage dips to choose equipment for use in their installations. Voltage tolerance curves are a suitable method for this. Selection of equipment in an industrial process requires your customer to balance between the costs associated with process interruptions and the costs of equipment. To make the trade-off it is important that your customer has information available on the immunity of different equipment against voltage dips. Voltage tolerance curves are a suitable method to quantify this equipment immunity against voltage dips. Analysing these curves, the customer can easily determine the performance of the equipment he has selected for his installation and make an economic trade-off. The abovementioned final report gives a systematic method for obtaining these voltage-tolerance curves.

The voltage-dip immunity label simplifies communication between equipment manufacturers and their customers. The voltage-dip immunity label is a method based on the voltage tolerance curve and the performance criterion, and it allows customers to communicate, in an easier way, their requirements to the manufacturer. The label consists of the immunity class and the performance criterion. Based on their experience and knowledge, manufacturers are strongly encouraged to provide feedback on the proposed classes, and even to propose adjustments. Manufacturers of equipment should be aware that there is a demand for highly-immune equipment as well as for cheap low-immunity equipment. 


\section{Further development of voltage-dip immunity labels}

Equipment manufacturers should get involved in the further development of voltage-dip immunity labels. Besides satisfying the basic standard requirements, a welldeveloped voltage-dip immunity label is the best way of addressing new market segments of customers with different immunity requirements. It is therefore of prime interest for equipment manufacturers to be involved in the development of such a label. The experience of equipment manufacturers in voltage dip compatibility of the equipment they are manufacturing and as well the effectiveness of the "labelling" concept will bring realworld value to the process of labelling. It is therefore important that equipment manufacturers get actively involved in the development of voltage-dip labels.

\section{Message to manufacturers of power- quality monitoring equipment}

A. In a three-phase system, distinguish between Type I, Type II and Type III voltage dips

Next to residual voltage and duration according to IEC 61000-4-30, additional information should be provided about the dip. The most important additional information concerns the type of dip with respect to the three-phase unbalance of the voltages during the dip. The abovementioned working group proposes the use of a classification into three types, Type I, Type II, and Type III. A memo written by UIE Working Group "Power Quality" further defines the method for extracting the dip type and characteristics from measured voltage dips. These methods should be implemented in power-quality monitors and in analysis software because information on the dip type is required by both network operators and industrial customers sensitive to voltage dips.

\section{B. Contribute to the development of suitable additional voltage-dip characteristics}

In the above-mentioned final report it is shown that voltage dips require more characteristics than just residual voltage and duration. The type of voltage dip is one such additional characteristic but more such characteristics are needed. Examples of such characteristics are phase-angle jump and point-on-wave. Statistical information on these characteristics is lacking which in turn makes it difficult to assess their full impact on the performance of equipment and installations. Manufacturers of power-quality monitoring equipment and analysis software are encouraged to develop suitable methods for extracting these additional characteristics from recorded voltage waveforms. Sharing of the experience gained by this and cooperation with universities is highly encouraged.

\section{Present statistical results in the form of contour charts and percentiles}

When information from voltage dips over a longer period is available, this should be presented in the form of a voltage-dip contour chart or a similar method. It is thereby essential that the number of dips is given as a function of residual voltage as well as duration, for Type I, Type II and Type III separately. Giving the number of dips only as a function of the residual voltage is insufficient.

When information from multiple locations is available, the number of dips as in the previous paragraph should be given for a number of percentiles, for example the 50, 75 and 95 percentiles. Giving only the average over all sites is insufficient.

The above-mentioned final report describes the methods for presenting voltage-dip statistics in detail.

\section{Conclusion}

Voltage-dip immunity is an important issue for improving the compatibility between industrial installations on the electricity supply. This involves several aspects including immunity testing and of individual devices, improving the immunity of complete installations, and presenting the results from measurement campaigns in an appropriate way.

Voltage-dip immunity involves several stakeholders, nine of which have been addressed by UIE WG2. Individual messages to these nine stakeholders have been formulated. This paper summarized the messages to the six main stakeholders indentified by the working groups. In total there are nine stakeholders. The stakeholders researchers, educators, and small and medium-sized enterprises have not been covered in this paper. Details on those can be found on the webpage of the Union of Electricity Applications (UIE) [2].

\section{Acknowledgement}

The material presented in this paper is the result from CIGRE/CIRED/UIE Joint Working Group C4.110 and UIE Working Group 2. The following persons contributed to these working groups, beyond the authors: Bill Brumsickle, David Chapman, Felipe Córcoles López, Alastair Ferguson, Philipe Goossens, Roberto Chouhy Leborgne, Pierre Ligot, Andreia Leiria, Patrick Marteyn, Alex McEachern, John Mentzer, Ian McMichael, Jan Meyer, Jovica Milanovic, Ulrich Minnaar, Mohammed Redha, Mark Stephens, S.C. Vegunta, Francisc Zavoda, and Jin Zhong.

\section{References}

[1] CIGRE/CIRED/UIE JWG C4.110, Voltage dip immunity of equipment and installations, CIGRE Technical Brochure 412, published in 2010.

[2] UIE, http://www.uie.org/powerquality 